\title{
A PRODUÇÃO DO GÊNERO NA/DA CULTURA POPULAR: PROBLEMATIZANDO UM HABITUS DE GÊENERO JUNINO
}

Hayeska Costa Barroso ${ }^{1}$

Resumo: Os festejos juninos, no Brasil, constituem um campo de práticas que envolvem questões culturais, políticas, sociais e econômicas. O modo como os sujeitos estruturam e são estruturados nesse cenário envolve não somente o lugar que ocupam e/ou a função que desempenham. Na maioria das abordagens sobre tradições, culturas populares e festas, a maneira como estes mesmos sujeitos constituem sua subjetividade e como esta afeta a própria configuração da festa, seu modos operandi, não tem sido a tônica predominante. Questões relativas ao gênero, à sexualidade, à raça/etnia e aos aspectos geracionais, contudo, atravessam as celebrações festivas e seus ritos de consagração coletivos. É mister, portanto, visibilizá-los, de modo a desvendar como se expressam no campo e quais os seus significados na teia de relações e disputas, materiais e simbólicas, que encerram. Assim, a presente pesquisa objetiva investigar as expressões e os códigos de gênero e sexualidades no campo da festa junina em Fortaleza-Ce. Metodologicamente falando, a quadrilha junina é aqui considerada o momento privilegiado em que se opera a observação destes aspectos, sobretudo a performatividade do gênero associada ao contínuo processo de espetacularização da festa. A premissa inicial é de que algumas festas e manifestações da cultura popular, a exemplo da festa junina, do carnaval, da festa do boi e do maracatu, são essencialmente generificadas a partir de um prisma heteronormativo; o que não impede a reedição de símbolos tradicionais sob os quais elas mesmas foram engendradas, sobretudo no que tange aos papeis sociais de gênero e à sexualidade, constituindo um habitus de gênero que, ora tensiona e subverte determinados padrões, ora ratifica-os.

Palavras-chave: Festa Junina. Espetacularização. Performatividade. Gênero.

Abstract: The June festivities in Brazil constitute a field of practices involving cultural, political, social and economic issues. The way that agents structure and are structured in this scenario involves not only the place they occupy and / or the role they play. In most approaches to traditions, popular cultures, and parties, the way these same agents constitute their subjectivity and how it affects the very configuration of the feast, its modus operandi, has not been the predominant tonic. Issues relating to gender, sexuality, race / ethnicity, and generational aspects, however, cross festive celebrations and their collective rites of consecration. It is necessary, therefore, to make them visible, in order to discover how they are expressed in the field and what the meanings they contain in the web of relations and disputes, both material and symbolic. Thus, the present research aims to investigate the expressions and codes of gender and sexualities in the field of the June party in Fortaleza-Ce. Methodologically speaking, the junina group is considered the privileged moment in which the observation of these aspects is performed, especially the performative character of the

\footnotetext{
${ }^{1}$ Docente do Curso de Serviço Social da Universidade de Brasília (UnB). Doutoranda em Sociologia pela Universidade Federal do Ceará (UFC). Mestre em Políticas Públicas e Sociedade pela Universidade Estadual do Ceará (UECE). Assistente Social. E-mail: hayeskacb@gmail.com. ORCID: https://orcid.org/0000-0002-8280$\underline{7187 .}$
} 
genre associated with the continuous process of spectacularization of the party. The premise is that some festivals and manifestations of popular culture, such as the June festival, the carnival, the feast of the ox and the maracatu, are essentially generated from a heteronormative prism; which does not prevent the reissue of traditional symbols under which they themselves were engendered, especially in relation to gender roles and sexuality, constituting a gender habitus that sometimes stresses and subverts certain patterns, and ratifies them.

Keywords: June Celebration. Spectacularization. Performativity. Gender.

\section{Introdução}

A presente pesquisa se propõe a desvendar as interfaces entre uma sociologia da produção simbólica da festa junina e a capacidade de o gênero se (re)editar nessa manifestação da cultura popular. A celebração do matrimônio tradicional é o mote para a festa em questão, a qual parece definir papeis em se tratando das damas e cavalheiros. Mais recentemente, contudo, tais papeis de gênero tem passado por transformações e ressignificações, a exemplo da presença das performances trans.

Questionamo-nos, portanto, como se materializa a relação do feminino e do masculino nesse contexto, em que medida os papeis de gênero estruturam ou são estruturados pela festa. É possível, por exemplo, identificar algo de subversivo nas performances trans ali efetivadas? Que discursos e práticas reiteram os papeis tradicionais de gênero, e quais caminhos de fuga redefinem esses mesmos papeis no bojo das tradições? O gênero nesta festa parece envolver, tão logo, práticas sociais, a própria produção simbólica da festa, mas também, e, sobretudo, discursos sobre tradição, masculinidades e feminilidades.

A festa junina e sua produção envolvem múltiplos signos quanto aos papeis de gênero. Tal multiplicidade impõe-nos questionamentos outros, tais como: os papeis sociais de gênero na cultura popular junina são produtos desta ou são produzidos por ela, estruturam-na ou são por ela estruturados? Dessa forma, envolvemo-nos na busca pela identificação dos atores dessa festa, que compõem e ocupam o campo, o qual parece ser revelador de tensões e disputas relativas às questões de gênero. $\mathrm{O}$ campo da pesquisa está centrado no "circuito oficial dos festejos juninos" (BARROSO, 2013) do estado do Ceará, com destaque para as competições e festivais realizados na capital cearense, Fortaleza. Assim, o campo festivo, ou o sistema da festa (BOURDIEU, 1996), trata-se de uma série de eventos de apresentação e festivais de competição entre quadrilhas juninas, promovidos, principalmente, entre os meses de junho e julho. 
São considerados eventos oficiais aqueles que possuem algum tipo de vinculação institucional com entes públicos e/ou privados e que compõem a agenda e o cronograma de apresentação dos grupos juninos. Geralmente, ocorrem nos finais de semana e tendem a redefinir a dinâmica dos espaços onde são realizados na cidade, sobretudo quando em praças e logradouros públicos. Tais eventos dão visibilidade aos grupos juninos e, além de aglutinar o público em geral, conta com um público espectador especializado em acompanhar as quadrilhas juninas (como se fossem fã-clubes), torcidas organizadas. Ainda que estejam envoltos pelo debate da competição que lhe acabou sendo inerente, os festivais demonstram ter a capacidade de desterritorializar e deslocar os grupos de quadrilhas juninas de seus bairros de origem, de suas cidades. Todo processo de reconhecimento e visibilidade pelo qual passou a festa junina perpassa também por esses deslocamentos que possibilitam intercâmbios e trocas as mais diversas.

Estamos diante, portanto, da empiria da festa (AMARAL, 2012). Nesse contexto é que os grupos juninos realizam suas apresentações em espetáculos normatizados por aquilo que ousamos chamar de "regras do jogo", as quais impõem uma série de obrigações e exigências aos grupos a fim de que os mesmos sejam avaliados por uma comissão julgadora, que define e delimita o que pode ou não pode ser considerado "tradição junina". Este estudo, portanto, trata-se de um recorte da pesquisa de tese de doutoramento em Sociologia, pela Universidade Federal do Ceará, e apresenta resultados parciais oriundos de participação no campo da pesquisa por meio de observações, entrevistas e diários de campo, realizados desde meados do ano 2015.

Metodologicamente falando, a quadrilha junina é aqui considerada o momento privilegiado em que se opera a observação destes aspectos, sobretudo a performatividade do gênero associada ao contínuo processo de espetacularização da festa. É em torno e a partir dela que a festa consagra seu ritual coletivo, envolvendo a dança, a música, o teatro, a moda e $\mathrm{o}$ artesanato. A presença de sujeitos trans quadrilheiros, assumindo o papel de brincantes dançarinos, foi o ponto de partida para os questionamentos iniciais da investigação. Dentre as demais estratégias acionadas para a coleta de dados em pesquisa de campo, ressalta-se a pesquisa documental, a qual tem sido realizada considerando documentos institucionais e levantamentos em jornais. Os primeiros podem ser classificados a partir da natureza das instituições: públicos (a saber, Secretaria de Cultura do Estado do Ceará - SECULT, e Secretaria de Cultura de Fortaleza - SECULTFOR) e privados (sobretudo, as entidades representativas e organizativas do movimento junino, como: Federação das Quadrilhas Juninas do Ceará - FEQUAJUCE, e União Junina do Ceará). Das instituições públicas, foram 
acessadas informações relativas aos editais públicos de fomento às atividades juninas no estado e em Fortaleza. Das privadas, os dados foram, principalmente, relativos aos cadastros e filiações dos grupos de quadrilhas juninas cearenses.

Os levantamentos em jornais (ainda em fase de organização e classificação) tomaram por base pesquisa no Núcleo de Microfilmagem da Biblioteca Pública Governador Menezes Pimentel (BPGMP) nos dois jornais impressos de maior circulação do estado, Diário do Nordeste e O Povo. O recorte temporal se deu a partir do ano de 1995 até 2017, nos meses de maio, junho e julho, período que nomeamos por temporada junina ${ }^{2}$. A delimitação histórica justifica-se por uma das hipóteses iniciais desta pesquisa se apoiar na intrínseca relação entre os contornos que a política pública cultural local ganha no trânsito do final da década de 1990 para o início dos anos 2000, notoriamente sob a forma de uma política de editais, aliada à intensificação do processo de espetacularização das festas juninas, ponto de inflexão de sua crescente regulação e normatização, inaugurando uma nova relação entre Estado e sociedade civil no campo dos festejos juninos.

Ainda no tocante à metodologia, entrevistas abertas, ou melhor, conversas informais, com sujeitos que ocupam posição estratégica no campo deram elementos para identificar possíveis e futuros interlocutores, cujos critérios de inclusão, a priori, são: função desempenhada no espetáculo no tocante aos papeis de gênero e às sexualidades, relação com grupos juninos de grande porte, nível de incidência/influência nas decisões de um grupo, e conhecimento da máquina que move o modo de fazer a festa junina.

\section{Reconhecendo a festa junina no Ceará como campo de pesquisa}

O mês de junho guarda uma das principais marcas da cultura popular sertanejonordestina: a festa junina. Os festejos juninos, no Brasil, constituem um campo de práticas que envolvem questões culturais, políticas, sociais e econômicas. O modo como os sujeitos estruturam e são estruturados nesse cenário envolve não somente o lugar que ocupam e/ou a função que desempenham. Na maioria das abordagens sobre tradições, culturas populares e festas, a maneira como estes mesmos sujeitos constituem sua subjetividade e como esta afeta a própria configuração da festa, seu modos operandi, não tem sido a tônica predominante. Alguns estudos situam-nos como: "mecanismo institucional do entretenimento-turismo" (FARIAS, 2011); pela perspectiva antropológica (CAVALCANTI, 2013) ou folclorista

\footnotetext{
${ }^{2}$ Em Belém-Pa, Noleto (2016) nomeia esse mesmo período de quadra junina.
} 
(CASCUDO, 1969; 1964); pela espetacularização nos tempos atuais (CASTRO, 2012) no espaço urbano; na área mais abrangente das chamadas "festas à brasileira" (AMARAL, 1998); a partir da "dimensão musical da experiência festiva" (MENEZES NETO, 2015); com ênfase no aspecto coreográfico da dança (LEAL, 2004); ou até mesmo problematizando a relação campo-cidade na vivência juvenil da quadrilha junina (CHIANCA, 2007a) ou a religiosidade na celebração e devoção de santos (CHIANCA, 2007b)

De início, parece-nos que já superamos parte das leituras que tendem a abordar as festas populares em geral como um campo claramente definido, bem como aquelas que insistem em recair na busca de elementos ditos 'tradicionais', 'vocacionais' e ‘originais'. Não nos furtamos, no entanto, deste debate, o qual também faz parte dos inúmeros movimentos, teóricos e empíricos, sociais e individuais, pelos quais a festa junina tem passado. Assim, na condição de pesquisadora, nos posicionamos socialmente como admiradora e público participante da festa; apenas após sua apreensão metodológica, contudo, é que fomos capazes de ir além do encantamento próprio aos primeiros olhares.

Questões relativas ao gênero, à sexualidade, à raça/etnia e aos aspectos geracionais, contudo, atravessam as celebrações festivas e seus ritos de consagração coletivos. Gênero e sexualidade são dispositivos nas/das festas populares brasileiras. Noleto $(2016 ; 2014)$ traz uma valorosa contribuição neste horizonte temático ao abordar a interseccionalidade entre gênero, raça e sexualidade como constitutivos dos sujeitos na realidade da festa junina em Belém, Pará. Numa tentativa de desvendar como as "culturas populares constituem os sujeitos" (NOLETO, 2016, p. 15), o autor considera que este ponto de vista tem sido preterido da maioria dos estudos, os quais tendem a enfatizar seu anverso, ou seja, como os sujeitos constituem as culturas populares ${ }^{3}$.

Reconhecemos, para tanto, o vasto e diversificado repertório de práticas e linguagens que subjazem a este cenário. Falamos de diferentes expressões artísticas e culturais, desde a dança, o teatro, a música, o artesanato, passando pela moda, gastronomia e turismo. A premissa inicial é de que algumas festas e manifestações da cultura popular, a exemplo da festa junina, do carnaval, da festa do boi e do maracatu, são essencialmente generificadas a partir de um prisma heteronormativo; o que não impede a reedição de símbolos tradicionais sob os quais elas mesmas foram engendradas, sobretudo no que tange aos papeis sociais de

\footnotetext{
${ }^{3}$ Para fins desta introdução, esta problemática parece inócua, na medida em que consideramos que sujeitos e culturas populares constituem-se simultaneamente no processo histórico. Logo, é imprescindível desvendar tanto a constituição dos sujeitos pelas culturas populares, como destas por aqueles, sob o risco de esvaziar ou fragmentar a apreensão da totalidade do processo em curso.
} 
gênero e à sexualidade, constituindo um habitus de gênero que, ora tensiona e subverte determinados padrões, ora ratifica-os.

Conforme Farias e Mira (2014, p. 24), “falar em cultura popular, no Brasil, é chamar a atenção para os modos de vida e de sobrevivência, mas, igualmente, para os universos simbólicos com seus sistemas de práticas significantes”. Convergem, portanto, no campo festivo, cadeias produtivas, arranjos produtivos locais, bem como a intermediação e o consumo de bens intangíveis. A festa junina, tão logo, realiza-se como um evento, capaz de imbricar, no mesmo contexto, experiências individuais, coletivas e sociais variadas (TAVARES, 2012), redesenhadas de modo contínuo e processual, dada sua intersecção com o entretenimento (FARIAS e MIRA, 2014) e o turismo.

É necessário ressaltar que aqui tomamos como referência a realidade dos grandes grupos de quadrilha junina cearense ${ }^{4}$, os quais apresentam espetáculos de grande porte, contam com denso aparato tecnológico e cenográfico, uma pluralidade de recursos e linguagens artísticas, e que, talvez por esses aspectos, tornaram-se referência e objeto de inspiração (para não dizer também imitação) de vários outros grupos. Estes apresentam orçamentos anuais de produção que giram em torno de $\mathrm{R} \$ 200.000,00$ (duzentos mil reais) a mais de $\mathrm{R} \$ 500.000,00$ (meio milhão de reais) ${ }^{5}$, possuem forte engajamento nas redes sociais ${ }^{6}$, com perfis com mais de 30 mil seguidores, e tendem a monopolizar (com certa alternância entre si) as primeiras colocações (de primeiro ao terceiro lugar) nos festivais de competição local, estadual e nacional. Com essas características, poderíamos elencar no máximo uns cinco grupos. Embora esse número possa ser considerado baixo, é o suficiente para erguer aquilo que chamamos de ethos hegemônico e dominante da/na festa junina cearense.

Os concursos e campeonatos entre as quadrilhas juninas ocorrem nos meses de junho e julho, delineando o que nomeamos em outro momento de circuito oficial dos festejos juninos (BARROSO, 2013). A normatização imposta pela realidade dos concursos altera substantivamente a semântica e a morfologia das festas juninas. Os festivais podem ser promovidos por meio do fomento dos editais públicos a: pessoas físicas, "com atuação comprovada como organizador(a), produtor(a) ou brincante envolvido (a) na organização da Quadrilha Junina inscrita” (CEARÁ, 2018); ou, pessoa jurídica “de direito público do estado

\footnotetext{
${ }^{4}$ Castro (2018) considera que esse perfil está intimamente relacionado à participação das quadrilhas juninas em competições cuja premiação são valores em dinheiro, os chamados festivais, intensificada nas últimas décadas, embora não delimite de modo preciso a que período se refere.

${ }^{5}$ Informações presentes no Relatório Final da Pesquisa do Edital dos Festejos Juninos em Fortaleza, realizada pela SECULTFOR no ano de 2017, a qual foi coordenada por esta pesquisadora.

6 Alguns grupos possuem uma equipe específica responsável pelas mídias sociais, estando presentes em múltiplas plataformas simultaneamente: youtube, facebook, instagram e twitter.
} 
do Ceará ou instituição da administração pública municipal (direta ou indireta), responsável pelas atividades culturais do município candidato ou com histórico de atuação no campo cultural" (CEARÁ, 2018). As entidades representativas e organizativas do movimento junino (sobretudo, FEQUAJUCE e União Junina do Ceará) também promovem, cada uma, seus respectivos festivais/campeonatos estaduais.

Há, ainda, festivais que escapam a essas possibilidades, e são promovidos, sem qualquer recurso público direto, por lideranças comunitárias, associações de moradores, ou até pela iniciativa privada, como tem sido perceptível nos últimos cinco anos a entrada dos shoppings centers ${ }^{7}$ nesse cenário como promotores de festivais. Talvez a emergência dos shoppings como loci possíveis para a realização dos festivais e de apresentações dos grupos esteja ligada a outro fenômeno característico do campo da festa junina: as características dos territórios onde eles ocorrem.

As periferias dos centros urbanos são os locais privilegiados de ocorrência dos festivais. Já nos municípios do interior, costumam ocupar os espaços mais centrais da vida pública daquelas cidades. Marcadas pela incidência de problemáticas sociais, tais como, violência urbana, insegurança, falta de estrutura básica (saneamento, pavimentação, iluminação pública), tráfico de drogas, marcas da vida nas grandes cidades e sintomáticas de uma frágil atuação do Estado como garantidor das condições de vida dos cidadãos, ali também, e, por conseguinte, pulsam as manifestações da cultura popular, a exemplo da festa junina. As quadras de escolas, ginásios poliesportivos, praças, ruas e logradouros convertemse no palco da festa naquele lapso temporal. Ainda que momentaneamente, aqueles espaços são ressignificados e ocupados. A festa é, às vezes, "um instrumento ao serviço de valorização

\footnotetext{
${ }^{7}$ Os shoppings centers geralmente selam parceria com uma das entidades juninas para a organização e promoção do festival. O pioneiro nesse ramo foi o North Shopping, ao convidar alguns grupos de quadrilhas para se apresentarem como 'atração' nas suas dependências. Em seguida, o shopping Benfica também passa a realizar as mesmas ações, com destaque para a participação de quadrilhas infantis, priorizado por este último. O North Shopping Jóquei e o Shopping Iguatemi despontaram 'cedendo' o espaço físico de seus estacionamentos abertos para que as entidades promovessem seus respectivos festivais estaduais. O Shopping Riomar Kennedy, contudo, tem se destacado no papel estratégico que vem desempenhando no cenário junino local. Além de ser patrocinador oficial do maior grupo do estado, promove exposição de indumentárias e cenários utilizados em uma galeria do shopping; sedia ensaios abertos de grandes grupos, sobretudo o Primeiro Ensaio, o qual costuma ser um evento destacado na programação anual do grupos; promove o "Bloquinho Junino", cuja primeira edição ocorreu em 2017, ou seja, um evento de bloco de carnaval com a temática junina realizado no estacionamento aberto; sedia o Maior Ensaio de Quadrilhas Juninas do Mundo, evento que teve sua segunda edição em 2018, e que reúne membros de grupos do interior do estado, de Fortaleza e Região Metropolitana. Neste ano, foram cerca de 300 pares em um grande ensaio unificado, sem diferenciações entre os grupos. Os 'templos do consumo' trouxeram para suas dependências mais essa possibilidade de consumir a cultura junina, já tão presente no apelo estético de sua decoração durante esse período, nas vitrines das lojas, nas 'comidas típicas' presentes na praça de alimentação. A este respeito, Bernié-Boissard (2004) reforça que "os espaços comerciais são lugares privilegiados de realização da festa" (p. 374), como uma gerência permanente da mercadoria, cuja finalidade é atrair e aumentar a clientela.
} 
do território" (BERNIÉ-BOISSARD, 2004, p. 373), de sua recomposição, o qual ganha uma funcionalidade diversa daquela que costuma ter no cotidiano, marcando o tempo e os ritmos das vidas individuais e coletivas. Como num intercâmbio de práticas festivas, as periferias ‘importam'/'exportam' seus grupos, possibilitam trocas materiais e simbólicas entre os atores dessa cena itinerante que a festa junina cria.

Ainda assim, um dado do qual não podemos fugir é a diminuição, ano após ano, do quantitativo do público espectador dos festivais de quadrilhas, conforme atesta o Relatório Final da Pesquisa sobre os Festejos Juninos de 2017 (FORTALEZA, 2017). O horário de início da maioria dos festivais ocorre após às $20 \mathrm{~h}$ e tende a se estender até depois de meia noite, o que também deve ser considerado em relação ao cenário da violência urbana que acomete a cidade.

O calendário é capaz de indicar, à maior parte das pessoas, o mês de junho como sendo aquele em que se celebram as festas juninas, afinal, as festas são juninas exatamente em referência ao mês em que ocorrem. De base mística e religiosa, a alusão a São João, São Pedro e Santo Antônio, santos que a Igreja Católica soleniza em seu calendário litúrgico nessa mesma época, são cada vez mais o argumento da festa e cada vez menos o mote de sua expressão espetacular, laicizada e secularizada das formas as mais diversas; uma delas é a quadrilha junina. Nas quadrilhas juninas, como espetáculo ritualizado, prevalecem os aspectos lúdicos, de entretenimento e estético, em detrimento dos aspectos místicos e religiosos.

O tempo do quadrilheiro transborda junho, alarga-se por todos os meses do ano, a delinear seu próprio calendário ${ }^{8}$ (ver Apêndice D). Matos (2014) utiliza a expressão "dilatar o tempo" da festa para falar sobre fenômeno semelhante que acomete a festa do Círio de Nazaré, onde se tem tido uma preocupação por parte dos organizadores de garantir uma “extensão do Círio no tempo e no espaço” (MATOS, 2014, p. 189). Desse modo, vive-se o espírito da festa o ano inteiro, num calendário junino intermitente. Em janeiro, iniciam-se os ensaios, geralmente ocorridos em quadras de escolas (públicas ou privadas), ou espaços como associações e centros comunitários. São feitas verdadeiras chamadas públicas de divulgação para esse primeiro ensaio aberto. Ali, os quadrilheiros se apresentam, manifestam interesse em dançar naquele respectivo grupo, fazem uma inscrição ${ }^{9}$, adquirem um kit (composto por

\footnotetext{
${ }^{8}$ No Apêndice D, esboçamos o que poderia ser chamado de calendário/cronograma quadrilheiro, de modo a indicar no tempo anual a localização dos processos e das etapas que envolvem a produção do espetáculo. Com isso, não queremos reduzir a complexidade inerente aos processos, nem tão pouco reduzi-los a uma abordagem linear e sequencial, mas, em geral, os grupos de grande porte adotam cronologia similar.

9 Alguns grupos chegam sim a cobrar uma taxa de inscrição neste momento, principalmente o tipo aqui considerado, grupos de grande porte. A maioria dos grupos não possui autonomia financeira e depende de algum tipo de patrocínio. Na capital, da iniciativa privada; no interior, dos governos municipais. Shoppings, grupos
} 
camisa temática do grupo ${ }^{10}$, garrafinha de água, sacolinha de pano e/ou algum souvenier do grupo). Alguns grupos tornaram essa ocasião verdadeiros eventos, em que se faz o lançamento da temática do grupo, apresentação dos destaques juninos (rainha/rei, noivo/noiva) com cerimonial digno de popstars da grande mídia. E, de fato, o são. Esses destaques possuem tanta projeção, status e reconhecimento no meio junino, ao ponto de existirem seus fã-clubes, fazerem "presença vip"11 em eventos de outros grupos juninos de menor porte e possuírem um staff próprio para a sua preparação para a temporada junina. Consideramos esse momento um evento no sentido de ser um acontecimento público, previamente organizado/planejado por uma equipe; envolvendo uma dinâmica bem mais complexa e estruturada do que propriamente um ensaio. Aos novos brincantes, normalmente oriundos de grupos menores em tamanho e estrutura, o encantamento é inevitável. Partilham, portanto, de um habitus junino, ou seja, princípios organizadores de suas práticas; logo, sacramenta-se este ponto de partida público ${ }^{12}$, faz-se uma grande quadrilha improvisada, "coletivamente orquestrada sem ser o produto da ação organizada de um maestro" (BOURDIEU, 2013, p.87), destituída de coreografia e/ou novos passos de dança, a consagrar aquele coletivo a partir de então.

No Ceará, também podemos observar a existência de equipes que cumprem a função de ser os mass media junino, uma mídia digital especializada em São João, a exemplo de portais, como o Portal Ispia e o Mídia Junina, os quais mantém uma multiplataforma online de conteúdo sobre as festas juninas: instagram, facebook e youtube, principalmente. Eles fazer a cobertura de eventos, realizam entrevistas exclusivas com as personalidades mais famosas do mundo junino e, mais recentemente, começaram a assumir o papel de promotores e organizadores de eventos ${ }^{13}$. Essas mídias são geralmente compostas por ex-quadrilheiros (brincantes, presidentes de quadrilha, jurados juninos).

\section{A identificação de um habitus de gênero junino: problematizando papeis sociais e performances}

empresarias, marcas de roupas/sapatos de grife, franquias de lojas de maquiagem e perfumarias, empresas de transporte privado, restaurantes, redes de supermercados e pequenos comerciantes locais estão entre os que patrocinam. Além disso, os grupos juninos promovem estratégias outras para arrecadar recursos antes da temporada, como bingos, rifas, quermesses, festas temáticas, concurso de Rainha Gay, feijoadas, além dos carnês de mensalidade pago pelos brincantes para custeio de sua indumentária.

${ }^{10}$ Durante todo o período de ensaios, os brincantes são solicitados, por parte da direção do grupo, para que usem a camisa durante os ensaios.

${ }^{11}$ Pelas quais recebem remuneração financeira.

${ }^{12}$ Consideramos ponto de partida público porque, na esfera privada, o pontapé inicial começou meses antes dessa ocasião.

${ }^{13}$ A exemplo do Maior Ensaio de Quadrilhas Juninas do Mundo, promovido em parceria com o Shopping RioMar Kennedy. 
O espraiamento do tempo festivo junino por todo o calendário anual possibilita, por exemplo, que seja comum escutar de um quadrilheiro que o "próximo São João começa imediatamente quando o atual acaba”. Outros tipos de concursos, mas que não podem ser considerados festivais ${ }^{14}$, haja vista serem competições individualizadas entre os concorrentes, sobretudo nos últimos dez anos, tem ocupado espaço na pré-temporada junina, ou seja, ocorrem antes do mês de junho. Trata-se dos concursos para escolher os destaques juninos, dentre eles a chamada Miss Caipira Gay/Rainha G/Rainha da Diversidade.

Noleto (2016) aponta que em Belém esses concursos ocorrem ao mesmo tempo dos concursos e festivais de quadrilha. No Ceará, eles configuram o cenário das pré-festas juninas, geralmente promovidas pelos grupos como possibilidade de arrecadar recursos financeiros ${ }^{15}$. Além disso, as entidades representativas do movimento junino também os promovem. São concursos para a eleição da melhor rainha ${ }^{16}$ (mulheres cisgênero ${ }^{17}$ ), casal de noivos, princesa (as mini rainhas das quadrilhas juninas infantis), e rainhas G ou Gay. Nesta última categoria, "concorrem homens homossexuais, travestis, mulheres transexuais e todo e qualquer sujeito que viva qualquer experiência com a transgeneridade" (NOLETO, 2016, p. 13), a partir da qual encerre na sua performance a própria experiência de feminilidade (NOLETO, 2016). Nem sempre as candidatas à Rainha Gay ${ }^{18}$ desempenham o papel feminino sui generis no interior de seus grupos juninos de pertencimento: as damas. Em Belém, conforme Noleto $(2016)^{19}$, o mundo junino é marcado por uma oposição binária entre transgeneridade e cisgeneridade, o que talvez não seja a tônica predominante no Ceará. Os sujeitos trans femininos, nos últimos tempos, também estão figurando na própria dinâmica interna dos

\footnotetext{
${ }^{14}$ Considera-se como festival de quadrilhas "eventos com programação cultural voltada para promoção e valorização dos festejos juninos, realizados em locais abertos e/ou cobertos e de fácil acesso ao público, contendo obrigatoriamente apresentações competitivas de quadrilhas juninas adultas incluindo casamento, grupo musical regional (com no mínimo sanfona, zabumba, triângulo e pandeiro), feira com comidas típicas do ciclo junino e, preferencialmente, programação adicional de manifestações artísticas regionais e da cultura tradicional popular." (CEARÁ, 2018)

${ }^{15}$ Para o evento, são vendidos ingressos, além da comercialização de comidas e bebidas no local.

${ }^{16}$ Nesse tipo de concurso, as rainhas dos grandes grupos juninos não chegam nem a competir. Geralmente são convidadas como juradas, haja vista o status e a sua reputação de celebridade do cenário quadrilheiro.

${ }^{17}$ Ou seja, mulheres que se identificam com o gênero determinado no momento de seu nascimento por ocasião de suas características fisiológicas. Assim, tem-se uma concordância entre a identidade de gênero (feminina) com o sexo biológico (mulher). Em pessoas trans, identidade de gênero e sexo biológico não coincidem, pondo em xeque a díade mulher-feminino e homem-masculino.

${ }^{18}$ Em Belém, tais eventos estão divididos em três categorias: miss caipira, mulata e morena.

19 A recorrência frequente à pesquisa de Noleto (2016) justifica-se pela afinidade do objeto em tela problematizado: a questão de gênero no contexto da festa junina. Ainda assim, a proximidade temática da pesquisa não elimina suas particularidades entre si, sobretudo em relação ao campo, não somente no sentido restrito de local em que se realiza. Falar de campo vai além de uma percepção estática e fixa de lugar; prescinde de um espaço simbólico, atravessado pelas lutas dos agentes, marcado por determinados signos e valores capazes de legitimar práticas individuais e coletivas. (BOURDIEU, 2013)
} 
grupos, dançam junto com os grupos, e não apenas para os concursos de pré-temporada junina $^{20}$.

Os festivais consideram quadrilha junina como uma dança de pares entre damas e cavalheiros, em comemoração a um casamento matuto. Prevalece, portanto, como o lugar de heterossexualidade hegemônica como um dos principais códigos da festa. No entanto, "o quadro é mais complexo do que parece, pois a diversidade sexual e de gênero está imiscuída em todo o processo de produção dos certames juninos e de apresentação das performances quadrilheiras" (NOLETO, 2016, p. 14). A presença de homens gays e homens trans a desempenhar a função de damas ${ }^{21}$ nas quadrilhas já é uma realidade local, regional e nacional, não se configurando apenas como fenômeno local (NOLETO, 2016). Os grupos juninos tem autonomia para a decisão de aceitar ou não performances trans em seus espetáculos. No Ceará, não se tem conhecimento de alguma regulação proibitiva dos concursos e competições nesse sentido, embora existam relatos que revelam certa resistência nesse processo de aceitação por parte, principalmente, do corpo de jurados juninos, responsável por avaliar os grupos durante os festivais. "A mais importante forma de classificação é aquela que se estrutura em torno de oposições binárias”, afirma Silva (2011, p. 82). Formas de classificação são, sobretudo, formas de dominação e controle ${ }^{22}$.

Predomina, tão logo, certa valorização da "expressão de feminilidades" na quadrilha junina, o que não seria suficiente para afirmar que a festa junina é uma festa feminina. Para Noleto (2016), tal fato pode ter afastado do cenário quadrilheiro a participação de mulheres lésbicas masculinizadas ou homens trans. Resta-nos problematizar: como pensar as identidades de gênero ali representadas e como se constituem neste campo? É mister pensar como essas identidades foram produzidas, para além de descrevê-las aqui e agora como se revelam em sua aparência. Quais mecanismos e instituições atuam diretamente na fixação desses papeis sociais de gênero na festa e como isto perpassa/afeta a criação das identidades generificadas/sexualizadas nesse contexto?

Para Woodward (2011), toda prática social é simbolicamente marcada, de modo que "a forma como vivemos nossas identidades sexuais é mediada pelos significados culturais sobre a sexualidade que são produzidos por meio de sistemas dominantes de representação"

\footnotetext{
${ }^{20} \mathrm{O}$ caso que será analisado noutro momento deste texto, contudo, figura como exceção, haja vista que a performance trans é exclusiva para os concursos individuais. No seu grupo de origem, o papel desempenhado no momento do espetáculo é de cavalheiro.

${ }^{21}$ Quem, então, tem desempenhado o papel de dama na quadrilha junina? Mulheres cis, mulheres trans, travestis e homens gays.

22 "A ordem social é mantida por meio de oposições binárias [...]. a produção de categorias pelas quais os indivíduos que transgridem são relegados [...] garante um certo controle social. a classificação simbólica está, assim, intimamente relacionada à ordem social" (WOODWARD, 2011, p. 47)
} 
(WOODWARD, 2011, p. 33). São produzidas imagens polifônicas que, ao mesmo tempo, podem nos reportar a uma gama variada de significações sobre: cultura popular, folclore, festa, entretenimento, políticas culturais, gênero, sexualidade, raça, classe social, cultura de massa, etc

A festa junina se tornou espaço poderoso de visibilidade trans/gay, ainda que continue a expressar aspectos de uma estrutura social predominamente heteronormativa e binária como padrão de gênero hegemônico. Como produto cultural que é, tal festa não está blindada às transformações contemporâneas em se tratando da abertura à pluralidade e heterogeneidade das questões relacionadas ao gênero. Noleto (2016) parte da premissa de que a festa junina produz sujeitos generificados, racializados e sexualizados. Na verdade, ainda em processo de amadurecimento dos argumentos, não concordamos em parte com tal afirmação. As questões relativas ao gênero, à raça e à sexualidade não são exclusivas às festas; elas atravessam a vida em sociedade. Talvez na festa elas emerjam situadas no sistema de práticas da festa, como instância de consagração e cristalização dos papeis de gênero, os quais não possuem uma existência autônoma e/ou independente do quadro mais amplo da realidade social, sobretudo por meio da fixação de determinadas identidades como normas. Em se tratando de gênero, qual o quadro de valores representativos da cultura junina? Qual a relação desse quadro de valores e a possibilidade de sua recriação?

A participação LGBT nos contextos de produção da cultura popular é uma realidade no Brasil (NOLETO, 2016, p. 15; GREEN). Como pensar as novas formas de posicionamento e narrativas dos sujeitos no campo festivo das culturas populares? Seria a festa junina um instrumento de conquista de espaço físico e simbólico para a população trans? As abordagens mais gerais sobre cultura popular e tradição tendem a invisibilizar a apreensão do lugar da produção também das subjetividades dos sujeitos que estruturam esse campo e, ao mesmo tempo, são estruturados por ele. Parece evidente que se trate de um habitus de gênero da cultura popular junina, estruturado a partir de uma performance cultural, que traz as marcas de uma forte e compulsória tradição heterossexual, no qual a fixidez dos papeis sociais e sexuais femininos e masculinos não foi capaz de limitar rotas de possibilidades de reedições desses mesmos papeis por meio de novas expressões da sexualidade, as quais orbitam em torno, sobretudo, de questões relativas à identidade de gênero feminina. Assim, as técnicas do corpo (MAUSS, 2013) acionadas por ocasião do espetáculo são indicadoras da dimensão generificada da/na composição coreográfica da quadrilha junina, encerrando aquilo Noleto (2016) chamou de "heterossexualidade coreografada". 
O casamento é uma expressão ritual e performática do espetáculo festivo, um 'cartão de visitas' da quadrilha junina. Nele ficam evidentes a linha temática e os personagens principais. Muitas vezes, o casamento é o pressuposto para tentar explicar ao público espectador a temática escolhida e sua relação com a cultura popular junina. Busca-se um processo de justaposição temática, ou mesmo, no que Canclini chamou de hibridação. Nem sempre se consegue. Aqueles mais saudosos do enredo tradicional do casamento, vêem com bastante ressalva a incidência de temáticas as mais diversas ${ }^{23}$ ou que não estão diretamente relacionadas ao contexto do campo, do sertão, onde se imagina que estão alocadas as 'raízes' da festa junina.

Sobre a entrada e participação dos sujeitos nesse campo festivo, Noleto (2016) considera que a festa junina é democrática e está aberta à participação de todos aqueles que assim o desejarem. Pensar a partir da lógica do circuito oficial dos concursos e festivais, associado à crescente mercantilização da celebração dessa festa, coloca-nos diante de um notório recorte de classe que se impôs ao celebrar. Talvez a percepção do autor possa ser ratificada fora desse circuito, onde o modos operandi da quadrilha junina ainda está mais ligado aos processos coletivos de mobilização e organização comunitária, de modo autônomo, espontâneo, a exemplo das festas escolares nas colégios de periferia, ou mesmo aquelas ‘quadrilhas improvisadas' que figuram nas celebrações de aniversários, confraternizações de empresa, dentre outros.

\section{Considerações finais}

Alguns pontos merecem destaque diante do quadro empírico ora evidenciado. $\mathrm{O}$ primeiro diz respeito ao fato de que as performances trans nos festejos juninos ratificam o pressuposto teórico de que as questões relativas aos papeis sociais de gênero e às identidades de gênero são instáveis e encerram possibilidades de agência e subversão por parte dos indivíduos, isso porque não estamos falando de uma simples encenação de um processo histórico em constante devir. A instabilidade dos binarismos assentados na lógica homemmacho e mulher-fêmea e gay e hétero confirmam o paradoxo do gênero nas festas juninas: as performances trans só devem ser consideradas subversivas quando puserem em xeque esses

\footnotetext{
${ }^{23}$ Alguns temas abordados tendem a se aproximar mais do imaginário ideal do sertanejo nordestino (ALVES, 2011), da vida no campo, onde se insistem em situar aquilo considerado como tradicional na festa junina. Assim, algumas temáticas presentes na temporada junina de 2018 são consideradas mais próximas dessa 'tradição', tais como: a seca, o artesanato de renda, a devoção aos santos, o cangaço (talvez o tema mais presente no São João, uma das muitas tradições inventadas nesse campo), o cordel, o pescador, etc. Outros temas, como cinema, novela, religiões de matriz africana, são considerados como inovações, expressões da modernidade na festa.
} 
mesmos binarismos. Se não são de todo subversivas, pois não permitem a descaracterização da díade masculino/feminino, explícita por meio das coreografias e indumentárias (NOLETO, 2014), ao menos os desestabilizam. É mister, ainda, reconhecer que "a luta para afirmar as diferentes identidades tem causas e consequências materiais" (WOODWARD, 2011, p. 10), e estão intimamente enraizadas nas condições sociais e matérias de vida dos sujeitos.

Os concursos de Rainhas G colocam no centro da festa a legitimação pública da feminilidade e da visibilidade de sujeitos trans, na medida em que

[...] homossexuais, travestis e pessoas "trans" (e não apenas aqueles que disputam os concursos, mas aqueles que assistem aos concursos) têm um momento ritualizado no qual são autorizados pelos poderes públicos a assumir um protagonismo que reconfigura os sentidos desses espaços ocupados, destituindo-os de seus "detentores" rotineiros e de seus significados cotidianos (desterritorializando-os) e dando-lhes novos "donos", novos usos e uma nova semântica (reterritorializando-os). (NOLETO, 2014, p.103)

Parece inegável o espaço conquistado e ocupado pelos sujeitos LGBT na festa junina. Sua participação se realiza de modo ativo, quer como espectadores, quer como brincantes, quer como produtores do espetáculo. Uma das hipóteses levantadas, portanto, considera que: os padrões de gênero, bem como suas mudanças e/ou manutenções, expressos nos rituais espetacularizados da festa junina, são um continuum dos padrões de gênero da vida social; assim, tal qual vivenciamos nas estruturas sociais contemporâneas um "afrouxamento" da/na vivência e expressão da sexualidade, assim também a estrutura da festa possibilita a assimilação de novos códigos definidores dos papéis de gênero. É em Elias também que encontramos o argumento para afirmar que é possível que muitos desses "novos" códigos e/ou papéis de gênero não tenham sido criados, intencional e previsivelmente, por alguém ou por um grupo, e que sua direção seja desconhecida por parte deste.

Os sistemas classificatórios, o "nós" e os "eles", as mulheres cis e as trans, não são apenas sistemas classificatórios das diferenças, mas sim de como as relações sociais tendem a ser organizadas e divididas. A marcação das identidades e das diferenças visualizada na festa junina no tocante ao gênero e à sexualidade, na verdade, é reveladora de como os sistemas classificatórios operam nas relações sociais em geral. Assim, nos furtamos a uma abordagem que torne excepcional os aspectos relativos à dinâmica da festa, como se estivessem apartados e/ou desenraizados das bases das relações sociais em geral, vivida e produzida pelos sujeitos em seu cotidiano.

A festa junina, enquanto manifestação da cultura popular, possibilita "dar sentido à experiência e ao tornar possível optar, entre as varias identidades possíveis, por um modo 
específico de subjetividade" (WOODWARD, 2011, p. 19). Nela, novas identidades podem ser desestabilizadas, mas também desestabilizadoras, num cenário em que "algumas diferenças são marcadas, [...] mas algumas podem ser [não intencionalmente] obscurecidas" (WOODWARD, 2011, p. 14) ${ }^{24}$. Nesse caso, podemos afirmar que, ao passo que as diferenças relativas à identidade de gênero e à sexualidade ficam nitidamente demarcadas pela presença das performances trans, as desigualdades inerentes aos papeis sociais de homens e mulheres tende a ser relativizada ou nem mesmo problematizada nesse cenário, como se fosse natural aquilo que é considerado feminino e masculino, qualificando o que convencionamos chamar de habitus de gênero.

\section{Referências bibliográficas}

ALBUQUERQUE JUNIOR, Durval Muniz. Fragmentos do discurso cultural: por uma análise crítica do discurso sobre a cultura no Brasil. In: NUSSBAUMER, Gisele (org.) Teorias e políticas da cultura. Salvador: EDUFBA, 2007.

ALVES, Elder Patrick Maia. A economia simbólica da cultura popular sertanejo-nordestina. Maceió: EDUFAL, 2011.

AMARAL, Rita de Cássia de Melo Peixoto. Para uma antropologia da festa: questões metodológico-organizativas do campo festivo brasileiro. In: PEREZ, Léa Freitas; AMARAL, Leila.; MESQUITA, Wania. (Orgs.). Festa como perspectiva e em perspectiva. Rio de Janeiro: Garamon, 2012. (p. 67-86).

Festa à brasileira: significados do festejar, no "país que não é sério". Tese de Doutorado (Antropologia), Universidade de São Paulo, São Paulo, 1998.

BARROSO, Hayeska Costa. "O São João é gay!": horizontes interpretativos sobre as perfomances trans na festa junina no Ceará. Revista Periodicus. n. 6, v. 1, 2017. p. 179-197.

. Mercadores da tradição: os usos da tradição nas quadrilhas juninas no Ceará. Revista

Políticas Públicas \& Cidades. v. 3, n.3, set/dez, 2015, p. 42-63

"Prepare seu coração pras coisas que eu vou contar...": um ensaio sobre a dinâmica das quadrilhas juninas no Ceará. Dissertação de Mestrado (Políticas Públicas e Sociedade), Universidade Estadual do Ceará, Fortaleza-Ceará, 2013.

BERNIÉ-BOISSARD, Catherine. A cidade em festas: símbolos de identidades, lugar de resistência? In: Revista Cidades. v. 8, n. 13, 2011. (p. 233-261)

BOURDIEU, Pierre. O Senso Prático. Trad. Maria Ferreira. 3 ed. Petrópolis, RJ: Vozes, 2013. (Coleção Sociologia)

BUTLER, Judith. Corpos que pesam: sobre os limites discursivos do "sexo". In: LOURO, Guacira Lopes (Org.). O corpo educado: pedagogias da sexualidade. Trad. Tomaz Tadeu da Silva. 3 ed. Belo Horizonte: Autêntica Editora, 2013. (p.151-172)

Problemas de gênero: feminismo e subversão da identidade. Trad. Renato Aguiar. Rio de Janeiro: Civilização Brasileira, 2003.

Actos performativos y constitución del género: un ensayo sobre fenomenología y teoría feminista. Debate Feminista, v. 18, octubre, 1998.

24 "Os agentes jamais sabem completamente o que eles fazem que o que fazem tem mais sentido do imaginam" (BOURDIEU, 2013, p. 113) 
CANCLINI, Nestor. Culturas híbridas. Estratégias para entrar e sair da modernidade. São Paulo: EDUSP, 2000.

Culturas populares no capitalismo. São Paulo: Editora Brasiliense, 1989.

CASCUDO, Luís da Câmara. Folclore do Brasil: pesquisas e notas. Brasil/Lisboa: Fundo de Cultura, 1969.

Dicionário do Folclore Brasileiro. Rio de Janeiro: Ediouro, 1954.

CASTRO, Janio Roque Barros de. Da casa à praça pública: a espetacularização das festas juninas no espaço urbano. Salvador: EDUFBA, 2012.

. As manifestações culturais no contexto das festas juninas espetacularizadas da cidade de Cachoeira, no Recôncavo baiano. In: BARTHE-DELOIZY, F.; SERPA, A. (Orgs.) Visões do Brasil: estudos culturais em Geografia [online]. Salvador: EDUFBA; Edições L'Harmattan, 2012, p. 113-126.

CASTRO, Thiago Silva de. Política das relações quadrilheiras: um estudo a partir da experiência do grupo competitivo Estrela do Luar, em Sobral/CE. Dissertação (Mestrado em Antropologia Social), Universidade Federal do Rio Grande do Norte, 2018.

CAVALCANTI, Maria Laura Viveiros de Castro. Os sentidos do espetáculo. Revista de Antropologia, 45 (1), 2002, p. 37-78.

. Carnaval carioca: dos bastidores ao desfile. Rio de Janeiro: UFRJ, 2006.

Drama social: notas sobre um tema de Victor Turner. Cadernos de Campo, n. 16, 2007, p. 127-137.

Tempo e narrativa nos folguedos do boi. In: Cavalcanti, Maria Laura; Gonçalves, José Reginaldo (Orgs.). As festas e os dias: ritos e sociabilidades festivas. Rio de Janeiro: Contra Capa, 2009, p. 93-114.

CHIANCA, Luciana de Oliveira. O auxílio luxuoso da sanfona: tradição, espetáculo e mídia nos concursos de quadrilhas juninas. Revista Observatório Itaú Cultural, n. 14 (mai. 2013). São Paulo: Itaú Cultural, 2013.

Quando o campo está na cidade: migração, identidade e festa. Revista Sociedade e Cultura, v. 10, n. 1, Jan./Jun. 2007a, p. 45-59.

Devoção e diversão: Expressões contemporâneas de festas e santos católicos. Revista Anthropológicas, ano 11, volume 18(2), 2007b, p. 49-74.

. A festa do interior: migração e nostalgia na festa junina de Natal no século XX. EDUFRN, 2006.

COELHO, Juliana Frota da Justa. Descortinando a cidade: a "Montagem" da Fortaleza "Babado". Revista Latino-Americana de Geografia e Gênero, Ponta Grossa, v. 1, n. 2, p. 176189, ago/dez. 2010.

Bastidores e estreias: performers trans e boates gays "abalando" a cidade. Fortaleza, 2009. 156f. Dissertação (Mestrado em Sociologia). Programa de Pós-Graduação em Sociologia, Universidade Federal do Ceará, Fortaleza-Ce, 2009.

CRAPANZANO, Vincent. A cena: lançando sombra sobre o real. Revista Mana, n. 11(2), p. 357-383, 2005.

CRUZ, Danielle Maia. Fortaleza em tempo de carnaval: blocos, maracatus e a política de editais. Fortaleza, 2013. Tese de Doutorado (Sociologia). Universidade Federal do Ceará. Fortaleza-Ce.

CUCHE, Dennys. A noção de cultura nas ciências sociais. Bauru: EDUSC, 2002.

DUVIGNAUD, Jean. Festas e civilizações. Tradução de L. F. Raposo Fontenelle. Fortaleza: UFCE/Rio de Janeiro: Tempo Brasileiro, 1983.

ELIAS, Norbert. O processo civilizador: Uma história dos costumes. Volume 1. Rio de Janeiro: Zahar, 2011.

O processo civilizador. Volume 2. Rio de Janeiro: Zahar, 1993. 
A sociedade de corte: investigação sobre a sociologia da realeza e da sociedade de corte. Rio de Janeiro: Zahar, 2001.

FARIAS, Edson. A cultura popular na fisionomia da economia simbólica no Brasil. Teoria \& Pesquisa, v. XVI, n. 01, jan/jun de 2007.

Faces de uma festa-espetáculo: redes e diversidade na montagem do ciclo junino em Caruaru. Revista Sociedade e Cultura, v. 8, n. 1, 2005.

FARIAS, Edson Silva de.; MIRA, Maria Celeste. (Orgs.) Faces contemporâneas da cultura popular. Jundiaí: Paco Editorial, 2014.

FARIAS, Edson Silva de. Humano demasiado humano: entretenimento, economia simbólica e forma cultural na configuração contemporânea do popular. In: FARIAS, Edson Silva de.; MIRA, Maria Celeste. (Orgs.) Faces contemporâneas da cultura popular. Jundiaí: Paco Editorial, 2014. (p. 33-74)

GIOVANNINI JUNIOR, Oswaldo. Caxambu de Marafunda: ritual, memória e relações sociais. In: PEREZ, Léa Freitas.; AMARAL, Leila.; MESQUITA, Wania. (Orgs.). Festa como perspectiva e em perspectiva. Rio de Janeiro: Garamon, 2012. (p. 175-196)

GREEN, James Naylor. A homossexualidade masculina no Brasil do século XX. Trad. Cristina Fino e Cássio Arantes Leite. São Paulo: Editora UNESP, 2000.

HALL, Stuart. Identidade cultural e diáspora. Revista Comunicação \& Cultura, n. ${ }^{\circ}$ 1, 2006, (p. 21-35).

LEAL, Eleonora. Contando o tempo: a evolução coreográfica das quadrilhas juninas em Belém do Pará. Dissertação (Mestrado em Artes Cênicas), Universidade Federal da Bahia, Salvador, 2004.

LE BRETON, David. Antropologia do corpo e modernidade. Trad. Fábio dos Santos Creder Lopes. Petrópolis, RJ: Vozes, 2011.

As paixões ordinárias: antropologia das emoções. Trad. Luís Alberto Salton Peretti. Petrópolis, RJ: Vozes, 2009.

LIGIÉRO, Zeca (Org.). Performance e Antropologia de Richard Schechner. Rio de Janeiro: Mauad, 2012.

LIMA, Elizabeth Christina de Andrade. A Fábrica dos Sonhos: a invenção da festa junina no espaço urbano. João Pessoa: Idéia, 2002.

LOURO, Guacira Lopes. Pedagogias da sexualidade. In: (Org.). O corpo educado: pedagogias da sexualidade. 3 ed. Belo Horizonte: Autêntica Editora, 2013. (p. 7-34).

MAGNANI, José Guilherme Cantor. De perto e de dentro: notas para uma etnografia urbana. Revista Brasileira de Ciências Sociais, v. 17, n. 49, p. 11-29, 2002.

MAIA, Elder. As indústrias da criatividade e a cultura popular sertanejo-nordestina. In: FARIAS, Edson Silva de.; MIRA, Maria Celeste. (Orgs.) Faces contemporâneas da cultura popular. Jundiaí: Paco Editorial, 2014. (p. 97-137)

MARQUES, Janote Pires. Festas de negros em Fortaleza: territórios, sociabilidades e reelaborações (1871-1900). Fortaleza: Expressão Gráfica, 2009.

MATOS, Lucília da Silva. Belém em festa: a economia lúdica da fé no Círio de Nazaré. In: FARIAS, Edson Silva de.; MIRA, Maria Celeste. (Orgs.) Faces contemporâneas da cultura popular. Jundiaí: Paco Editorial, 2014. (p. 187-207)

MAUSS, Marcel. Sociologia e Antropologia. São Paulo: Cosac \& Naify, 2003.

MENEZES, Eufrázia Cristina. A dimensão espetacular das festas públicas do Candomblé. In: PEREZ, Léa Freitas; AMARAL, Leila; MESQUITA, Wania. (Orgs.). Festa como perspectiva e em perspectiva. Rio de Janeiro: Garamon, 2012. (p. 131-150)

MENEZES, Paula Dutra Leão de. A (re)invenção do cotidiano: a transformação de festas populares em evento turístico (estudo de caso do São João de Campina Grande). Revista Cultur, ano $06-\mathrm{n}^{\circ} 01-\mathrm{Fev} / 2012$. 
MENEZES, Renata de Castro. Tradição e atualidade no estudo das festas: uma leitura de Saint Besse, de Robert Hertz. In: PEREZ, Léa Freitas.; AMARAL, Leila.; MESQUITA, Wania. (Orgs.). Festa como perspectiva e em perspectiva. Rio de Janeiro: Garamon, 2012. (p. 43-65)

MENEZES NETO, Hugo. Música e Festa na Perspectiva das Quadrilhas Juninas de Recife. Revista Anthropológicas. Ano 19, 26(1):103-133, 2015.

O balancê no Arraial da Capital: quadrilha e tradição no São João do Recife. Dissertação de Mestrado (Antropologia), Universidade Federal de Pernambuco, Recife, 2008. MESQUITA, Wania. Conversão na folia: o bloco evangélico no espaço do carnaval carioca. In: PEREZ, Léa Freitas.; AMARAL, Leila.; MESQUITA, Wania. (Orgs.). Festa como perspectiva e em perspectiva. Rio de Janeiro: Garamon, 2012. (p. 105-117)

MIRA, Maria Celeste. Entre a beleza do morto e a cultura viva: mediadores da cultura popular na São Paulo da virada do milênio. São Paulo: Intermeios,FAPESP, 2016.

Diversidade cultural em São Paulo: o "orgulho caipira". In: FARIAS, Edson Silva de.; MIRA, Maria Celeste. (Orgs.) Faces contemporâneas da cultura popular. Jundiaí: Paco Editorial, 2014. (p. 75-95)

O masculino e o feminino nas narrativas da cultura de massas ou o deslocamento do olhar. Revista Pagu, n. 21, p. 13-38, 2003.

MISKOLCI, Richard. Corpos elétricos: do assujeitamento à estética da existência. Estudos Feministas, Florianópolis, v. 7, n. 1-2, p. 681-693, 1999.

NEPOMUCENO, Saulo. Dos frevos motocar aos funks chiques: diversão e consumo nas dinâmicas do ethos funkeiro brasiliense. In: FARIAS, Edson Silva de.; MIRA, Maria Celeste. (Orgs.) Faces contemporâneas da cultura popular. Jundiaí: Paco Editorial, 2014. (p. 271-320) NÓBREGA, Zulmira. A festa do maior São João do mundo: dimensões culturais da festa junina na cidade de Campina Grande. Tese de Doutorado (Cultura e Sociedade), Universidade Federal da Bahia, Salvador, 2010.

NOLETO, Rafael da Silva. Brilham Estrelas de São João: gênero, raça e sexualidade em performance nas festas juninas de Belém - Pará. Tese de Doutorado (Antropologia). Universidade de São Paulo, São Paulo, 2016.

"Brilham estrelas de São João!": notas sobre os concursos de "Miss Caipira Gay" e "Miss Caipira Mix" em Belém (PA). Revista Latinoamericana Sexualidad, Salud y Sociedad. n. 18, dez./2014. p.74-110.

ORTIZ, Renato. Um outro território: ensaios sobre a mundialização. São Paulo: Olho Dagua, 2000.

PEIRANO, Mariza. Rituais ontem e hoje. Rio de Janeiro: Ed. Zahar, 2003.

PEREZ, Léa Freitas. Festa para além da festa. In: PEREZ, Léa Freitas.; AMARAL, Leila.; MESQUITA, Wania. (Orgs.). Festa como perspectiva e em perspectiva. Rio de Janeiro: Garamon, 2012. (p. 21-42)

Temas ou teorias? O estatuto das noções de ritual e performance. Campos - Revista de Antropologia Social, v. 7, n. 2, 2006.

SALIH, Sara. Judith Butler e a Teoria Queer. Trad. Guacira Lopes Louro. Belo Horizonte: Autêntica Editora, 2013.

SILVA, André Luiz da. Mediação cultural nos grupos de devoção popular: a batalha cultural dos moçambiqueiros paulistas. In: FARIAS, Edson Silva de.; MIRA, Maria Celeste. (Orgs.) Faces contemporâneas da cultura popular. Jundiaí: Paco Editorial, 2014. (p. 139-161)

SILVA, Tomaz Tadeu da. A produção social da identidade e da diferença. In: SILVA, Tomaz Tadeu da. (Org.). Identidade e diferença: a perspectiva dos estudos culturais. 10 ed. Petrópolis, RJ: Vozes, 2011. (p. 73-102). 
TAVARES, Fátima. Religião, festa e ritual como agenciamentos possíveis. In: PEREZ, Léa Freitas.; AMARAL, Leila.; MESQUITA, Wania. (Orgs.). Festa como perspectiva e em perspectiva. Rio de Janeiro: Garamon, 2012. (p. 119-130)

TINHORÃO, José Ramos. As festas no Brasil Colonial. São Paulo. Editora 34, 2000.

TRAVASSOS, Elizabeth. Música folclórica e movimentos culturais. Revista Debates. n. 6, 2002. (p. 89-113)

TURNER, Victor. Dramas, campos e metáforas: ação simbólica na sociedade humana. Trad. Fabiano de Morais. Niterói: Editora da Universidade Federal Fluminense, 2008.

Floresta de símbolos, aspectos do ritual Ndembu. Rio de Janeiro: EdUFF, 2005.

VALE, Alexandre Fleming Câmara. $O$ vôo da beleza: travestilidade e devir minoritário, 2005. Tese de Doutorado (Sociologia), Universidade Federal do Ceará, Fortaleza-Ce, 2005.

WEEKS, Jeffrey. O corpo e a sexualidade. In: LOURO, Guacira Lopes (Org.). O corpo educado: pedagogias da sexualidade. Trad. Tomaz Tadeu da Silva. 3 ed. Belo Horizonte: Autêntica Editora, 2013. (p.35-82).

WOODWARD, Kathryn. Identidade e diferença: uma introdução teórica e conceitual. In: SILVA, Tomaz Tadeu da. (Org.). Identidade e diferença: a perspectiva dos estudos culturais. 10 ed. Petrópolis, RJ: Vozes, 2011. (p. 7-72) 